\title{
CONF-950868--21
}

BNL -62254

\section{DEMONSTRATION OF CLOSE-COUPLED BARRIERS FOR SUBSURFACE CONTAINMENT OF BURIED WASTE*}

John Heiser

Brookhaven National Laboratory

Bldg. 830, P.O. Box 5000

Upton, NY 11973-5000
Brian Dwyer

Sandia National Laboratory

P.O. Box 5800, MS 0719

Albuquerque, NM 87185-0719

ARCEIVED

\section{ABSTRACT}

OCT 231995

The primary objective of this project is to develop and demonstrate a close-dpad Tartier for the containment of subsurface waste or contaminant migration. A close-coupled barrier is produced by first installing a conventional cement grout curtain followed by a thin lining of a polymer grout. The resultant barrier is a cement polymer composite that has economic benefits derived from the cement and performance benefits from the durable and resistant polymer layer. Close-coupled barrier technology is applicable for final, interim, or emergency containment of subsurface waste forms. Consequently, when considering the diversity of technology application, the construction emplacement and material technology maturity, general site operational requirements, and regulatory compliance incentives, the close-coupled barrier system provides an alternative for any hazardous or mixed waste remediation plan. This paper will discuss the installation of a close-coupled barrier and the subsequent integrity verification. The demonstration will take place at a cold site at the Hanford Geotechnical Test Facility, 400 Area, Hanford, Washington.

\section{INTRODUCTION}

Over the past five decades, the US Department of Energy (DOE) Complex sites have experienced numerous loss of confinement failures from underground storage tanks, piping systems, vaults, landfills, and other structures containing hazardous and mixed wastes. Consequently, efforts are being made to devise technologies that provide containment of waste sites either as a safety net to "catch" future contaminant leakage/migration or as an interim step while final remediation alternatives are developed. A subterranean barrier will increase the performance of the waste site and reduce the possibility of contaminant migration into local geologic media or groundwater. Failure to treat contamination in situ will also result in exorbitant restoration costs at a later date. In addition, the legal ramifications for not treating many of these waste sites could be detrimental to the responsible parties.

The primary objective of this project is to develop and demonstrate a close-coupled barrier technology capable of containing waste forms within their existing subsurface transport, disposal, or storage structures. A close-coupled barrier is produced by first installing a conventional cement grout

\footnotetext{
"This work was performed under the auspices of the U.S. Department of Energy.
} 
curtain followed by a thin lining of a polymer grout. The resultant barrier is a cement polymer composite that has economic benefits derived from the cement and performance benefits from the durable and resistant polymer layer. It is essential that materials (grouts) and emplacement techniques are compatible; therefore, they shall be developed and demonstrated simultaneously. This is not a trivial issue. Barrier materials must simultaneously be emplaceable, i.e., compatible with emplacement equipment and site geology, withstand a wide variety of chemical, thermal, physical and radiological conditions, and meet acceptable longevity requirements. The concept of close-coupled barrier technology is the combination the two technologies being developed at Brookhaven National Laboratory (BNL) and Sandia National Laboratories (SNL).

BNL has been developing improved polymer-grout barrier materials for applications where impermeability and long-term durability are required [1],[2]. These materials have been used extensively in many commercial applications such as sewage and brine handling systems and electrolytic baths. Polymer grouts are candidates for high quality barrier materials due to their impermeability to gases and liquids, combined with their resistance to radiation, acidic, and alkaline environments [3]. However, improved chemical and/or physical durability and performance increases the cost of the barrier grout.

SNL has been investigating placement methods and cementitious grouts for subsurface barriers. During the summer of FY94 SNL placed several pilot scale jet-grouted cement columns at a clean site near the Chemical Waste Landfill at Sandia. At the same time BNL was invited to demonstrate a polymer grout using the same placement equipment.

For a barrier where zero tolerance in leak rate is required it would be nearly impossible to achieve this goal using a cementitious grout. Large castings of hydraulic cements result invariably in cracking due to shrinkage, thermal stresses induced by the hydration reactions, and wet-dry cycling prevalent at arid sites. The improved, low permeability, high integrity polymer materials under investigation by BNL could achieve the permeability and durability goals, but might be costly. A joint venture was proposed by Brian Dwyer of SNL, John Heiser of BNL, and Steve Phillips (grouting contractor) of Westinghouse Hanford Company (WHC). SNL could design an economical cement grout curtain that would be used as a backdrop for the polymer curtain. A cementitious "bath tub" would be formed and the inside lined or flooded with a polymer binder. The resultant containment is a multibarrier of a cementitious grout followed by a polymer grout. The final composite barrier would have cost benefits from using mostly portland cement grout and have the performance benefits of the polymers from the inner lining.

Close-coupled barrier technology is applicable for final, interim, or emergency containment of subsurface waste forms. Consequently, when considering the diversity of technology application, the construction emplacement and material technology maturity, general site operational requirements, and regulatory compliance incentives, the close-coupled barrier system provides an alternative for any hazardous or mixed waste remediation plan. 


\section{DISCLAIMER}

This report was prepared as an account of work sponsored by an agency of the United States Government. Neither the United States Government nor any agency thereof, nor any of their employees, makes any warranty, express or implied, or assumes any legal liability or responsibility for the accuracy, completeness, or usefulness of any information, apparatus, product, or process disclosed, or represents that its use would not infringe privately owned rights. Reference herein to any specific commercial product, process, or service by trade name, trademark, manufacturer, or otherwise does not necessarily constitute or imply its endorsement, recommendation, or favoring by the United States Government or any agency thereof. The views and opinions of authors expressed herein do not necessarily state or reflect those of the United States Government or any agency thereof. 


\section{DISCLAIMER}

Portions of this document may be illegible in electronic image products. Images are produced from the best available original document. 
This demonstration is jointly funded by the Landfill Stabilization Focus Area (LFA) and the Plumes Focus Area (PFA). For the LFA close-coupled barriers have many applications. They can be used to contain buried waste and will provide a lower permeability, more durable and chemically resistant barrier than cement grout alone. The polymers are not expected to crack as easily as cement (wet-dry cycling) or slurry walls (solvent or organics). Close-coupled barriers are also useful in hot spot retrieval for containing contaminants while excavation and removal take place and may serve as shoring reducing the amount of contaminated soil. Utilization by PFA related projects include sealing off a source term (e.g., sealing a leaking UST or containing a subsurface spill of solvent) and preventing continued growth of a plume; thereby, fixing the volume of waste. A data subset of the technology developed from the close-coupled barrier demonstration will include grouting with polymers. Using polymers by themselves will also prove useful to the DOE complex. Plumes or source terms can be surrounded by an inexpensive (e.g., AC-400 acrylate grout) to improve remediation efficiency for such technologies as in-situ air stripping of VOCs.

\section{BACKGROUND}

During FY94 small scale configurations (v-trough, cone, and $7 \times 7$ matrix) using cementitious grouts were installed via jet grouting. A single column was installed using a polymer grout. The FY95 demonstration will install a conical configuration barrier that is large enough to simulate numerous real sites. The cement and polymer will be installed together forming a close-coupled or composite barrier (see Figure 1). FY94 testing consisted only of infiltration testing and lab analysis of core samples. For FY95 testing (evaluation) will be expanded to include more rigorous infiltration testing (leak test with TDR and soil moisture block probes strategically located), gas tracer evaluation and also stress monitoring of the waste form during grouting. The barrier will be constructed to surround a simulated waste site (tank-) configured in a landfill excavation. The tank has been chosen to simulate the waste forms that exist within the DOE Complex.

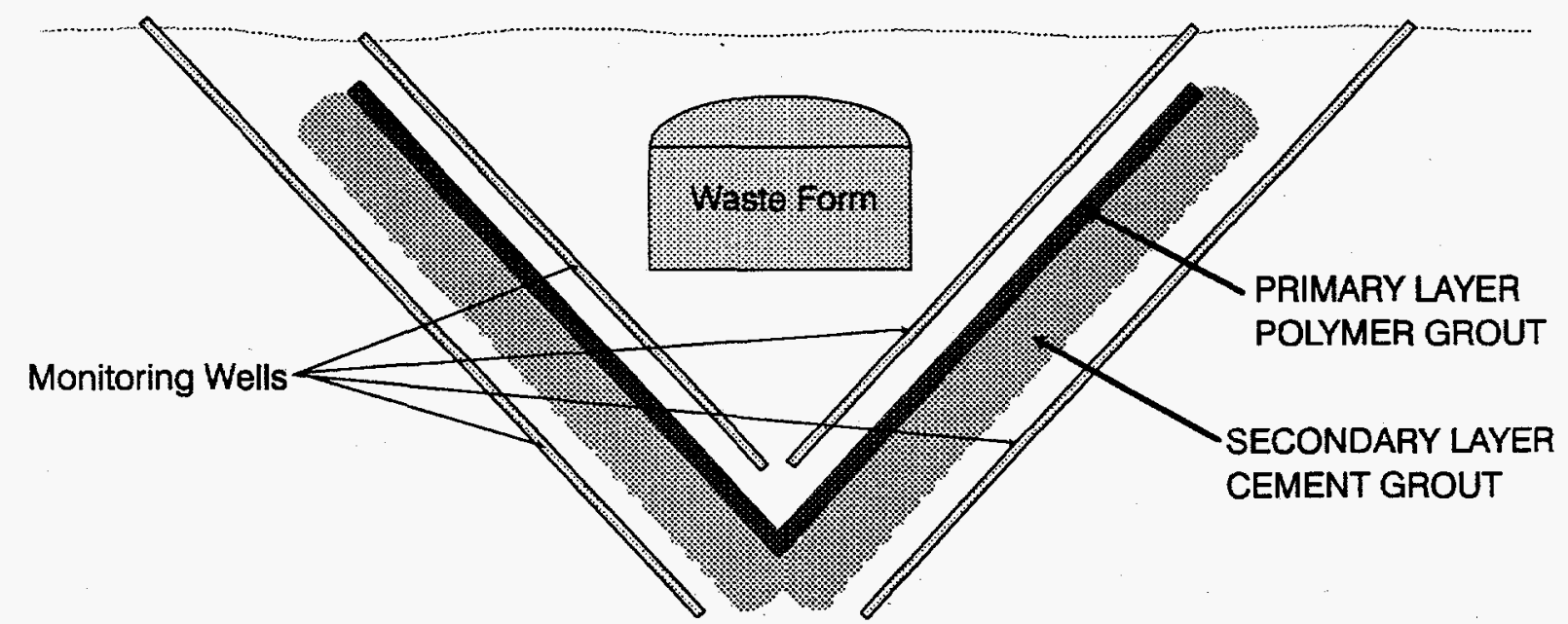

Figure 1. Schematic of Close-Coupled Barrier Demonstration 


\section{TEST SITE}

The site selected for the field-scale demonstration is the Geotechnical Test Facility (GTF) in the 400 Area ("Little Egypt") at the Hanford Site near Richland, Washington. This site was selected for several reasons: in geotechnical terms it is typical of many DOE facilities, the GTF is fully characterized and permitted for such a demonstration, the grouting contractor and required instrumentation and equipment (e.g., accelerometers, steel tank, etc.) is located nearby (eliminating mobilization/de-mobilization costs).

The GTF was completed in FY82. It was originally designed to test and demonstrate burial ground subsidence control methods. The site is NEPA approved and well characterized and is described in a report Construction and Preliminary Description of a Geotechnical Test Facility at the Hanford Site, Richland, Washington by Phillips and Fischer (Rockwell Hanford Operations SD-RETI-048). Potential end users were identified and include BNL (chemical and glass pit remediation), INEL (hot spot retrieval) and Hanford (close-coupled barriers for UST leak repair). The GTF (Hanford) soil is a coarse sand to gravel; BNL is a coarse sand, free of clay lenses or cobble; and INEL is an alluvial/eolian deposit consisting of fine clay sized silts to coarse gravels of carbonaceous origin overlying basalt.

Jet grouting has been accomplished in all soil types. Soil type affects the effective diameter (jetting distance) of the column, for example in a clay soil the jetting distance will be slightly reduced due to the energy absorbing characteristics of clay. This effect will be minimal and in the worst case will require slightly reduced spacing of the installation bore holes (columns) or increased jetting pressures. The biggest impediment soil type could impose to jetting would be large cobble that could block the jetting pathway, which could result in a gap in the barrier. It is anticipated that with a closecoupled approach the cobble will become part of one or both of the barrier layers (since the jetting would occur parallel and perpendicular to the cobble; column jetting followed by panel jetting). Therefore the success of the demonstration is virtually independent of the test site soil type.

Prior to the demonstration the site has been prepared by the subcontractor. This includes the burial and backfill of a 7500 liter tank and the installation of monitoring equipment. Monitoring wells are installed inside and outside the area to be enclosed by the barrier. These wells will be used for verification of the barrier integrity using perfluorocarbon tracers and for moisture determinations during water infiltration testing.

\section{BARRIER INSTALLATION}

This project will demonstrate a Systems Approach to construction of a subsurface barrier. This includes the integration of barrier materials, emplacement equipment, verification techniques, and post monitoring instrumentation to produce a close-coupled engineered barrier. The barrier materials and engineering placement systems portion of this technology are sufficiently mature to produce and demonstrate functionality During FY95. 
A full scale subsurface barrier consisting of two different materials shall be emplaced around and beneath a 7500 liter tank. The tank has been chosen to simulate the waste forms that exist within the DOE Complex. The stresses induced on the waste form shall be evaluated during barrier construction. This is an important part of a barrier emplacement because a miscalculation of the forces exerted on the waste form or structure could result in an unplanned release. After installation of each barrier layer the integrity of the barrier will be verified using PFT technology. After all verification is complete a static hydraulic head test will be performed to check for leakage while the barrier is under stress. Results will be applicable to construction of subsurface barriers throughout the DOE Complex and will have direct applicability to other government and private sector waste confinement actions. The technology will be applicable to construction of final, interim, and emergency barriers for a wide variety of waste/storage disposal sites.

The barrier will be constructed using conventional jet grouting techniques. Conventional jet grout curtains are constructed by injecting the grout through a pipe into the subsurface. The pipe has a drill tip on it which is used to drill the initial borehole. The pipe is then rotated while injecting the grout and slowly withdrawn from the ground. The high velocity jet masticates and intimately mixes the soil and grout which results in a column $\sim 1$ meter in diameter that resembles a pancake stack (Figure 2). After the grout pumped into the primary holes has gelled, secondary boreholes are drilled (in a honeycomb fashion) and grout is injected to fill gaps in the primary grout injection. This results in a barrier $1 \frac{1 / 2}{2}$ to 2 meters thick. Typically, the technique requires a pumpable grout that can be injected at pressures of $5000 \mathrm{psi}$ through a small orifice, typically $1 \mathrm{~mm}$. This limits any aggregate additions to fine particle sizes. Most often, the jet grouting uses a low viscosity grout ( $\sim 5 \mathrm{cps})$, and incorporates only the existing soils for aggregate. Jet grout curtains can be vertical using conventional drilling, or may be angled, or horizontal, using directional drilling.

Panel jet grouting is a simple refinement to conventional jet grouting. The tool is turned back and forth only a few degrees, rather than rotating the jetting tool $360^{\circ}$ and forming a cylindrical column. This forms a thin panel, typically 30-40 centimeters wide. Panels are laid side by side with a slight overlap in order to form a continuous barrier. This results in a significant reduction in the volume of grout required as opposed to the volume of grout required for column jet grouting.

The barrier will be emplaced with a track/trailer mounted modified jet grouting system. The secondary (cementitious) barrier will be placed first by column jet grouting and will be 1-2 meters thick. This layer will serve foremost as a backdrop for the polymer layer and secondly as a redundant, albeit less durable, barrier. The secondary layer is a thin layer of polymer ( 0.15 to 0.3 meters) applied to the inside of the cementitious barrier, reducing cost tremendously over full column grouting with polymers. Cementitious grouts are inexpensive (comparable to a slurry wall) and when cured give enough durability that the jetting action, when installing the polymer layer, will not "chew up" the secondary layer. 


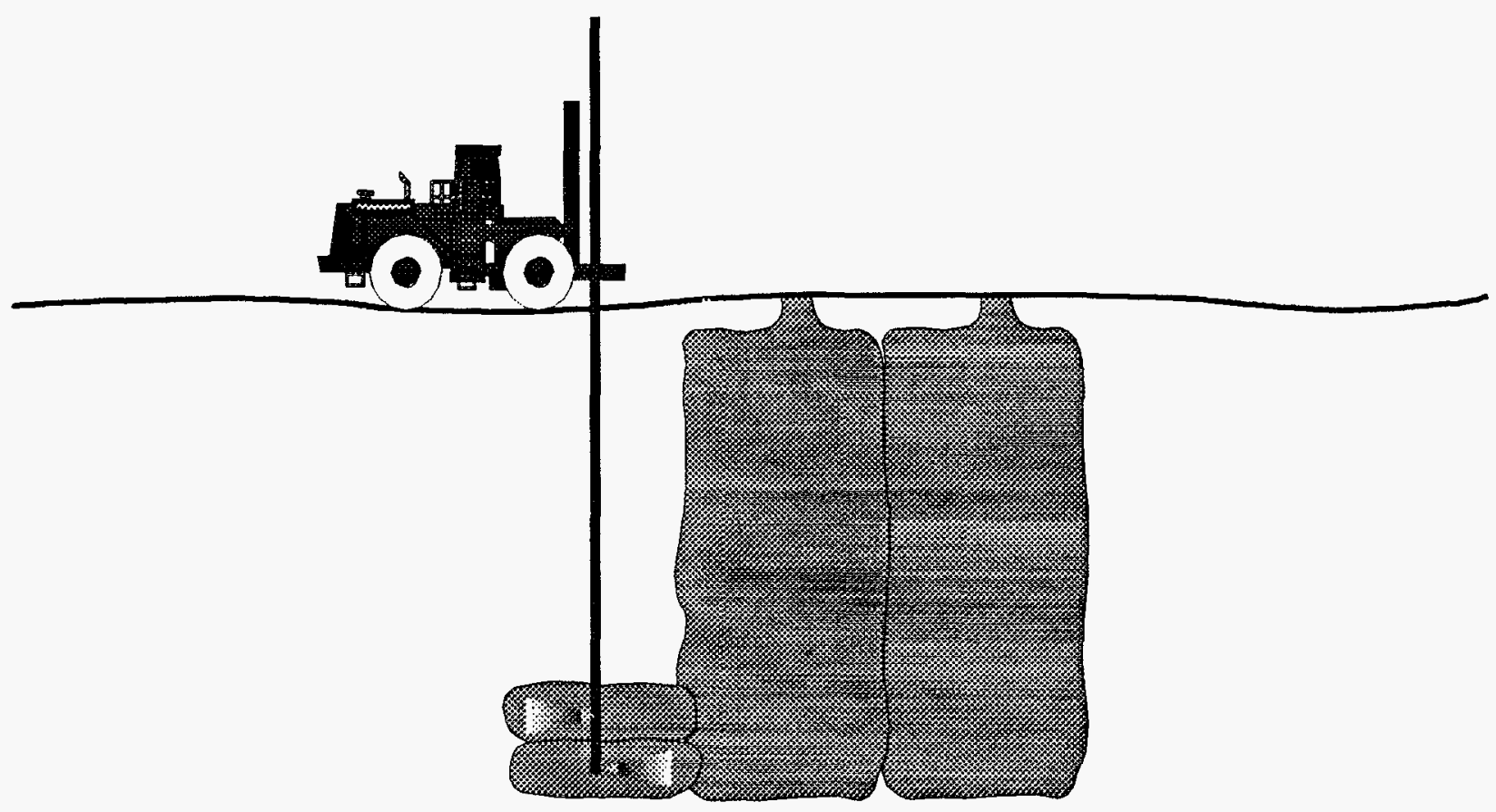

Figure 2. Conventional column jet grouting.

For this demonstration the drill rig will be a Casa Grande C 6 unit owned by the Westinghouse Hanford Company. The unit is depicted in Figure 3. Drilling will be completed at a $45^{\circ}$ angle to the ground, forming an ice cream cone shaped barrier (see Figure 1). One row of cement columns will be grouted in a circular pattern followed by a second row of columns behind and touching the first row in a honey comb fashion. The final barrier will be 41 feet in diameter at the top and extend approximately 23 to 24 feet below grade. For the demonstration the initial parameters will be optimized on-site using single column pilot tests prior to proceeding to the installation of the full scale barrier. Installation of the cement layer is scheduled to be completed by the end of July 1995 .

The primary barrier will be placed by panel jet-grouting and will be composed of a two part polymer grout. The polymer chosen is a high molecular weight acrylic manufactured by $3 \mathrm{M}$ Company. 3M and BNL are in the final process of formalizing a CRADA. 3M has provided and will continue to provide laboratory formulation and testing to meet the specific needs of the grouting demonstration. They will also provide expertise in the field during the construction phase of the demonstration. The resin is polymerized using a catalyst in combination with a promoter. The promoter is mixed in with half the monomer resins and the catalyst is mixed into the second half. Two separate tanks hold parts $A$ and $B$ and two separate pumps will be used to deliver the fluids for grouting. The polymerization reaction begins when parts $\mathrm{A}$ and $\mathrm{B}$ mix together in the ground. Dual wall drill pipe will be used so that the two separate grouting media can be simultaneously injected and therefore, the two fluids will be mixed together in the soil after leaving the drill stem. The mixing will occur as part of the soil mastication/mixing that occurs from the high pressure jetting. The polymer 
layer is scheduled to be installed in August 1995, following some preliminary verification activities on the cement curtain.

Successful demonstration of close-coupled barrier technology will be verified by operational testing, post operational monitoring, and destructive examination of the tank and geologic system. Specific criterion for measuring technology success include; formation hydraulic conductivity reduction of greater than two orders of magnitude, emplacement of primary and secondary barriers without compromising the integrity of the waste form (tank), and smooth integration of emplacement, barrier materials, verification, and post monitoring technologies, providing a comprehensive subsurface barrier program.

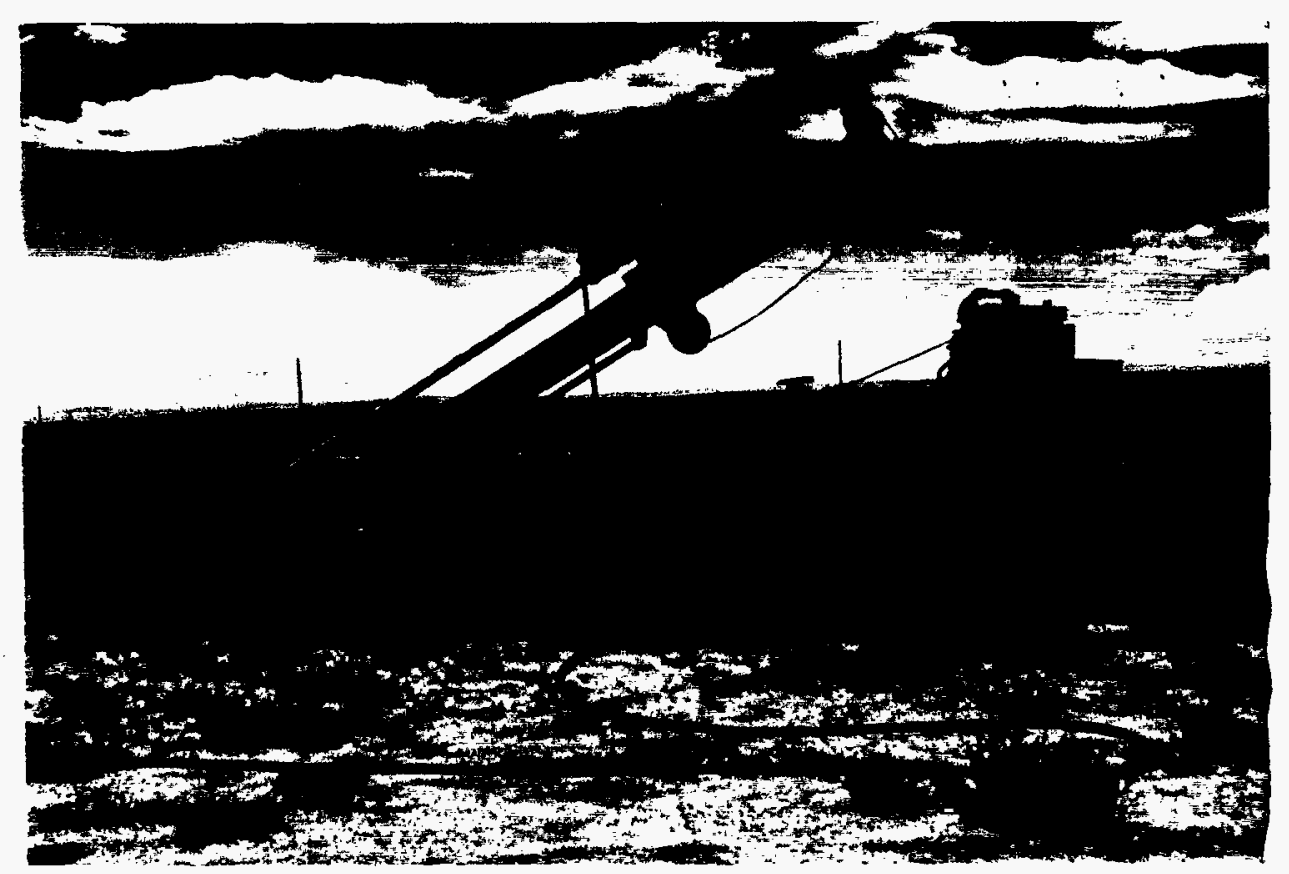

Figure 3. Casa Grande Jet Grouting Rig to be used at Hanford Demonstration.

\section{INTEGRITY VERIFICATION}

It is recognized that no suitable method exists for the verification of an emplaced barrier's integrity.[4] Because of the large size and deep placement of subsurface barriers detection of leaks is challenging. This becomes magnified if the permissible leakage from the site is low. Detection of small cracks (fractions of an inch) at depths of 100 feet or more has not been possible using existing surface geophysical techniques. Compounding the problem of locating flaws in a barrier is the fact that no placement technology can guarantee the completeness or integrity of the emplaced barrier. In jet grouting the borehole may become misaligned or the jet can be partially obstructed by cobble or varying soil types/densities, leaving a gap in the final barrier. Panel jet grouting may leave gaps between panels and/or at the junctions of horizontal and vertical barrier walls and may be thinner, and 
thus more prone to cracking. Additionally at the time of gel formation separations or "tears" may occur if localized settling takes place.

As a subtask to the barrier emplacement this project will demonstrate a method to verify the continuity of the barrier. Perfluorocarbon tracers (PFT) will be used to locate breaches in the barrier. It is expected that the demonstration will provide a proof-of-concept for gaseous tracer verification of barrier integrity and will give an estimate of the resolution of the technology.

PFT technology consists of the tracers themselves, injection techniques, samplers and analyzers. PFTs have negligible background concentrations of PFTs in the environment, consequently, only small quantities are needed. The tracers are nontoxic, nonreactive, nonflammable, environmentally safe (contains no chlorine), and commercially available. PFT technology is the most sensitive of all non-radioactive tracer technologies and concentrations in the range of 10 parts per quadrillion of air (ppq) can be routinely measured. The PFTs technology is a multi-tracer technology permitting up to six PFTs to be simultaneously deployed, sampled, and analyzed with the same instrumentation. This results in a lower cost and flexibility in experimental design and data interpretation. All six PFTs can be analyzed in 15 minutes on a laboratory based gas chromatograph.

Low detection limits allow detection of very small breaches in the barrier. Breaches will be located by injecting a series of PFTs on one side of a barrier wall and monitoring for those tracers on the other side. The injection and monitoring of the PFTs will be accomplished through vadose zone monitoring wells. The amount and type of tracer detected on the monitoring side of the barrier will determine the size and location of a breach. It is easy to see that the larger the opening in a barrier the greater the amount of tracer that transports across the barrier. Locating the breach requires more sophistication in the tracer methodology. Multiple tracer types can be injected at different points along the barrier (both vertical and horizontal). Investigation of the spectra of tracers coming through a breach then gives a location relative to the various tracer injection points.

The concentration of PFTs in the gas mixture will be determined using computer codes to make first approximations of expected dilutions during subsurface transport. Knowing we need a certain concentration external to the barrier in order to detect the tracer we can back calculate the required source term assuming certain gas permeability constants for the soil and barrier layers. These assumptions and model predictions will determine the initial sampling duration and number of samples. Based on the results of the first go round the sampling scheme will be varied in the field as needed.

\section{CONCLUSIONS}

Close-coupled barriers demonstrated by this task are applicable to final, interim, and emergency loss of confinement conditions. The technology is applicable to any buried or surface waste form that has the potential to release mobile contaminants. Unlike many other subsurface barrier technologies, close-coupled barriers are applicable to a wide range of waste materials and geohydrologic conditions. This is extremely advantageous because nearly every subsurface barrier 
has site specific conditions that require the flexibility offered by this technology, more specifically this technology offers an ability to place barrier materials that are compatible with virtually any waste form in almost any geologic setting.

End users for this technology include any DOE, state or commercial facility that has buried waste that may release contaminants to the environment at unacceptable levels. Specific end users have been identified and include Idaho National Engineering Laboratory (INEL), Brookhaven National Laboratory (BNL) and the Hanford reservation. INEL and BNL are interested in the full subsurface close-coupled barrier technology. Letters of support of the demonstration have been obtained from Lockheed Idaho for INEL and the DOE area office for BNL. Hanford has expressed interest in the use of polymers to form a close-coupled barrier. This technology could be used to seal leaks in the underground storage tanks at Hanford.

PFTs will allow locating and sizing of breaches at depth. The technology has regulatory acceptance and is used commercially for non-waste management practices (e.g. detecting leaks in underground power cables). This technology has been used in a variety of soils and locals and will be applicable to the entire DOE complex as well as commercial waste sites. The major use of tracers will be to verify placement continuity of a freshly emplaced barrier and to re-check corrective actions that may be used to seal or repair a breach. It may also be useful to periodically check a barrier to determine the long term integrity of the walls. This would certainly be beneficial if a cementitious grout (portland based) barrier were used. Cementitious grouts are prone to cracking from various degradation modes including wet-dry cycling which is prevalent at many of the DOE sites (e.g. Sandia and Hanford). Tracers would allow determination of performance losses in containment over the life of the barrier.

\section{REFERENCES}

1. Siskind, B. and J. Heiser, "Regulatory Issues and Assumptions Associated with Barriers in the Vadose Zone Surrounding Buried Waste", Environmental and Waste Technology Center, Brookhaven National Laboratory, Upton, NY, February 1993, BNL-48749.

2. Heiser, J.H. and P. Colombo, "Polymer Containment Barriers for Underground Storage Tanks", Waste Management '94, February 28 - March 3, 1994, Tucson, AZ..

3. Heiser, J.H. and L.W. Milian, "Laboratory Evaluation of Performance and Durability of Polymer Grouts for Subsurface Hydraulic/Diffusion Barriers", Brookhaven National Laboratory, Upton, NY, 1994, BNL-61292.

4. Heiser, J., "Subsurface Barrier Verification Technologies", Brookhaven National Laboratory, Upton, NY, June 1994, BNL-61127. 